\title{
Application and Study of Generative Design in Household Appliance Design
}

\author{
Haojun Wang
}

Hubei Business College, Wuhan, Hubei, 430079, China

760032265

Keywords: Generative design; household appliance; issues; suggestions

\begin{abstract}
Generative design is a design mode based on sophisticated analysis with the purpose of making design products diversified. The idea of generative design is of significance for the development of household appliances products, and a fully explored generative design will lead to more creative design of household appliance products and provide better household appliance products for consumers. This paper will offer suggestions aimed at tackling the insufficiencies of generative design application in the process of current design of household appliance products.
\end{abstract}

\section{Introduction}

Generative design is a relatively advanced idea focusing on design process. It advocates that infinite variety of design products can be made possible by increasing creativity in the process of design. It is crucial to introduce generative design into the development of more mature household appliance industry nowadays, so as to bring new vigor and vitality for the development of this industry.

\section{Status Quo of Generative Design's Application in Design of Household Appliance Products}

As a design idea, generative design is constantly studied by people in practice. In addition, researchers' understanding of generative design is constantly enriched in many aspects, and a case in point here would be the generative design's application in building industry which proves its validity. With the changes of market demands, household appliance industry sets higher and higher requirement for creativity of products, and generative design can meet this demand to a large extent in the rapid market changes. However, we have to admit that generative design is relative deficient in household appliance, and there also exists many issues needed to be considered.

\section{Issues Existing in Application of Generative Design in Household Appliance Products}

Compared with building industry, the application of generative design in household appliance industry is still in the embryonic stage, and there exists larger problems in the combination of product design with generative design in household appliance industry. For example, generative design is short of sophisticated analysis, and it pays more attention to results rather than process, and it is deficient of enough technical support, as shown in Fig. 1. 


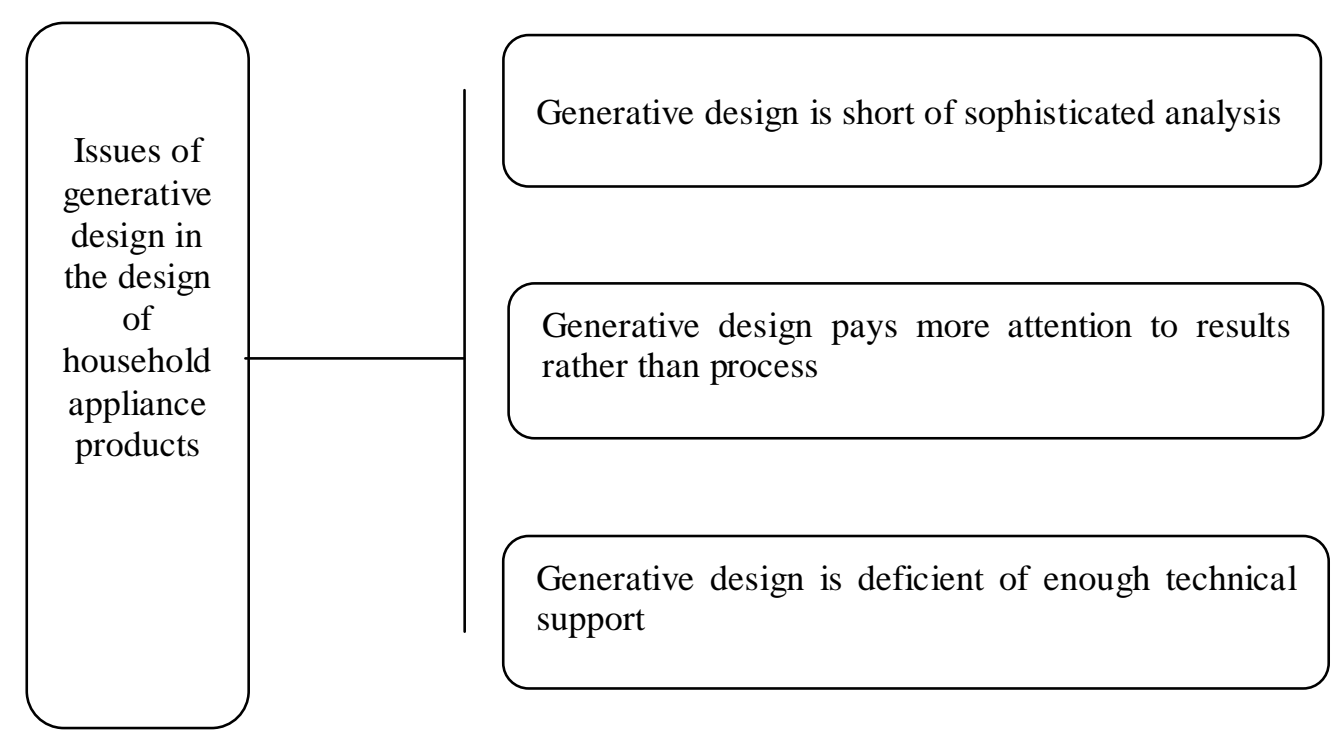

Figure 1. Finite Issues of generative design in the design of household appliance products

Generative Design in Household Appliance Products is Short of Sophisticated Analysis. Fundamentally, generative design is a deep analysis on concept, however, producers haven't formed good recognition on the theory of creativity produced in household appliance products in current household appliance market that lacks of thorough study. Generative design is difficult to serve for the design of household appliance products because its basic application has not built well.

Generative Design in Household Products Focuses More on Results rather than Process. Generative design has been heavily relying on the design process to spur the variety of results. Nevertheless, affected by traditional thought, most of designers still focus on finished product in product design. In this way, an idea can only produce one creative product. As a result, this idea can only lead to slow innovation efficiency, and it does not in line with the innovative idea of gen erative design.

Generative Design in Household Product is Lack of enough Technical Support. The most crucial part in generative design is to build a set of complete software and hardware supports specialized in serving household appliance production. The generative design of household appliance industry needs a set of system of generative design like Dreamcatcher, and the lacking of it makes it difficult for designers to implement design goal into design process.

\section{Suggestions on Enhancing Generative Design's Application in Household Appliance Products}

Aimed at resolving the issues of generative design existing in household appliance, the application of generative design should be improved from the three aspects: specifying the design goal and getting fundamental work well done; focusing on the process design of household appliance products and enhancing innovation; introducing cloud technology and applying it into the process of production design, as shown in Fig. 2. 


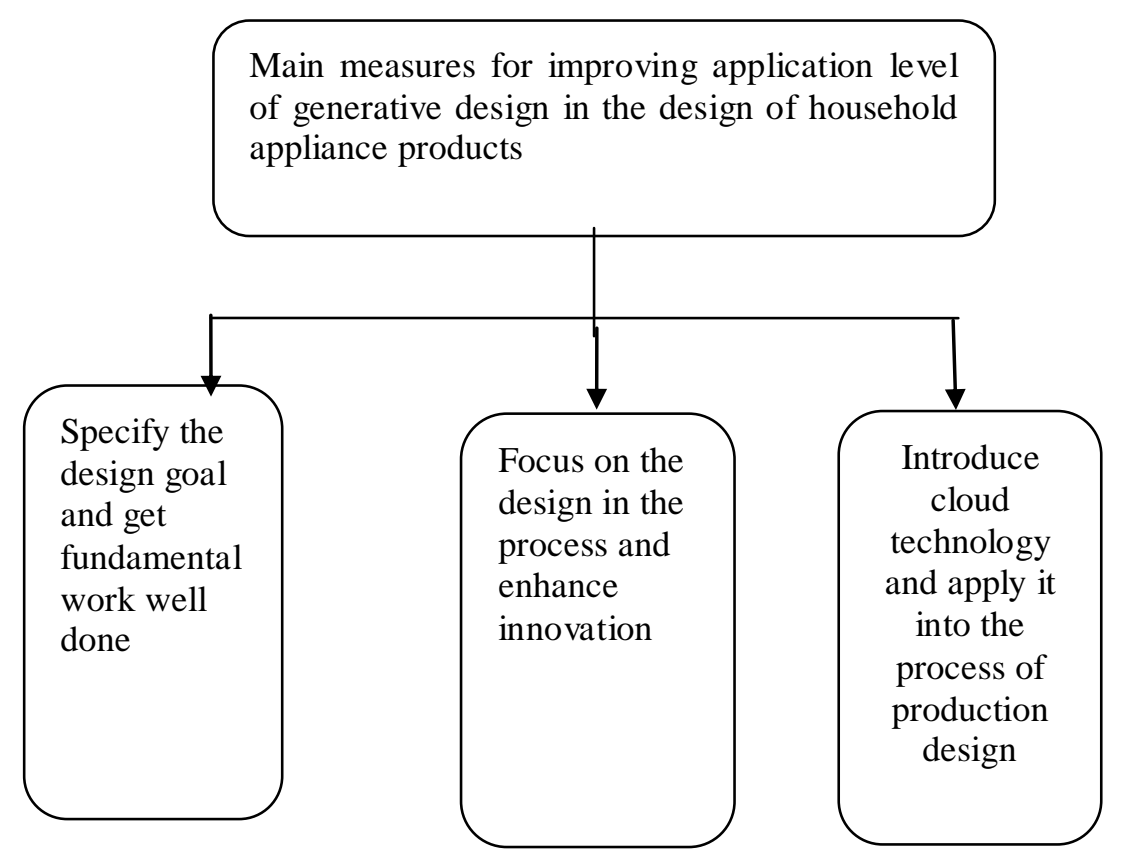

Figure 2. Finite Main measures for improving application of generative design in the design of household appliance products

Specify the Purpose of Design, and Get Fundamental Work of Generative Design well Done. The product design process in household appliance industry should be based on deep analysis of design idea, and specify the essence of creative design of household appliances. In order to create a good foundation for the perfect combination of generative design and products, designer's design idea-shaping and training should be done well, the design idea should be updated, and the thought of household appliances should be innovated in this session, laying a solid foundation for designers to better use the generative design. The beginning of generative design is that engineers should set the standard of products in advance, constraint the condition of product design, so the deep study on design purposes can be both fundamental and critical.

Focus on the Process design of Household Appliance Products, Making Creative Process drive Creative Finished Products. The creative design in design process of household appliance products is the core link in achieving results of generative design. In order to utilize generative design well, household appliance industry needs to invest a great deal of cost to collecting creative elements of household appliance, providing materials for the core of the generative design, namely the run of algorithm and logic. The design of a product may come from enlightenment in all aspects, so the enough accumulation of creative elements is important for preparation throughout the design process, which also provides a basis for simulation of design with cloud computing. It is in this process that a change from an idea to a product into an idea to many products is achieved. As the core is done better and better, the goal of diverse results can be achieved.

Reasonably Introduce cloud Technology, and Merge it into the process of Generative Design. The idea of generative design requires the support of cloud computing technology. Generative design relies more on computing, which produces creative products with very high computations through the permutations and combinations of different elements. Computation is the sole of generative design, so a large number of computation is certain to increase. Therefore, in order to meet the demand of big data, the generative design of household appliance products must conduct with the help of cloud computing to form an "autonomous" and creative combination from the processing of big data, thus completing the generative design from designer's instruction input into quick formation of creation. The cloud computing embedded with generative design makes the traditional design mode of household appliance designed for finished products change in nature, producing unlimited probabilities by means of cloud computing. 


\section{Conclusion}

As a design idea, generative design is undoubtedly more advanced and can save time, effort and costs compared with traditional one. It is believed that household appliance industry will go through great changes under this design idea. Household appliance products will have a bright future under generative design, so related industries should be committed themselves to solving the problems existing in the implementation of this design concept, making generative design concept can perfectly play its role in the design of household appliance products.

\section{References}

[1] Zhu Xiujuan. Application Study of Mechanical Design and Optimization in Small Household Appliances [J]. Journal of Mechanical transmission, 2011 (08):56-58.

[2] Wang, Y. L. "Construction Elements and Path of Practical Education Model in Universities" [J]. EURASIA Journal of Mathematics, Science and Technology, 2017, 13(10): 6775-6782.

[3] Song Jjinghua \& Wang Yaqi. Teaching Practice of the Course of Generative Design of Experimental Architecture [J]. New Architecture, 2017(06):126-130. 